\title{
Research of Informatization Solutions in Class Management
}

\author{
Shun Yao ${ }^{1}$, Genghuang Yang ${ }^{1,}$ a, Yingmei Zhang, Xiayi Hao \\ ${ }^{1}$ Tianjin Key Laboratory of Information Sensing and Intelligent Control, \\ Tianjin University of Technology and Education, China \\ aygenghuang@126.com
}

\begin{abstract}
Keywords: class management, educational informatization, office automation, DingTalk
Abstract. Education informatization is the ultimate goal of educational development. As the most important element of education system, good management of class is the guarantee of high teaching level and quality. The application of information technology in the course of class management, is combining the management mode with the mainstream "Internet + " technology, which breaks the traditional class management limited to the internal constraints of the campus, and realize the interaction among the four subjects of the class teacher, lesson teachers, students and parents. The informatization solutions highlights the system of class management and enhance the efficiency of class management. The functions of information technology in class management are analyzed, mainly based on the primary and secondary school class management problems and needs. Also, the functions in class management with the common platform of office automation software such as DingTalk is illustrated as an example. The real running proved the efficiency.
\end{abstract}

\section{Introduction}

Class is not just temporay family for learning, but also a platform that supporting face to face communication between teachers and students. Class management is applied to ensure the daily attendance of students as the foundation, and the goal is to enhance teacher-student affiliation, to expand students' horizons and increase students' knowledge. In traditional class management, the level of class management depends on the strength of managers ${ }^{[1]}$. In order to overcome the problem resulting from the basic process of laborious, inefficient in traditional class management, such as manual attendance registration, face-to-face notice, Internet is applied to link the teachers and students, and to improve the level of information, so as to improve the efficiency of class management.

\section{Problem Analysis in Class Management}

In traditional class education, teachers dominate the management process, while students are basically passive. The difficulty of management is different according to the quality of students and the ability of teachers. As the management between the teachers and students stays weak, there is no communication in deep mind. The class teacher spent too much time on student attendance, leave review, school notification and other matters. They have not enough energy to communicate with students. The communication between lesson teachers and students almost just happened in the classroom, and it is difficult to fully understand the satus of students' learning. The problem of learning in lessons can not be solved promptly. The teachers can only answer students' questions face to face in class, but can not share their opinions with students after class. The role of parents in student education is blurred. Due to time limit and geographical distance, the participation of parents is very few, and the frequency of communication is not enough to support the healthy 
development of students ${ }^{[2]}$.However parents concerning on students' learning and living conditions will affect their development as teachers do.

The main contradiction in class management is the dismatch between teachers and students. The main reason is that the class teacher have to face too many students which is beyond their ability. They can not take good care of the student when they are learning. The indirect reason is that little communication between the class teacher and the parents, leading to the lack of parental roles. Parents can not timely access to student's status and can not guide student to develop in good way. Ideal class management is that minimal management input result in teachers' ability, students' self-restraint, and parental involvement.And taking the advantages of human resource, material and finance resource is to cultivate the best students ${ }^{[3]}$.

\section{Analysis and Application of Educational Informatization}

The development of education informatization is a trend of this age. The main goals of the transformation in informatization development mechanism are the combination of informatization and education, and the sharing of excellent education resources ${ }^{[4]}$. The implementation of education information can reduce the difficulty of teacher management, meanwhile can improve the management level. The current development of education information is not ideal. Firstly, the capital construction of information technology compared to other areas is still relatively small, and mostly is disposable investment. The rapid development of information technology led to frequent replacement of products. If the modernity of information with social development can not be guaranteed, then the education informatization can not be sustained. Secondly, the construction of education informatization pays more attention to the hard environment construction, but ignores the improvement of the soft environment quality. For example, the government purchases the teaching equipment for school, but does not arrange the complete training for the teachers. The teachers can not put the information technology into use flexibly in the teaching process. Finally, the function of educational informatization can not be achieved ${ }^{[5]}$.

Investment costs and the using depth are the main issues in the promotion of information technology which should be combined with education, in order to achieve class management information ${ }^{[6]}$. The management platform of office automation - DingTalk is a popular software free for life, which only needs the certification of the enterprise. It can be established of the organizational structure to come into service. The teachers, students, parents can install software application on mobile phone to achieve class daily management, school notification, and resource sharing. Parents are involved in the class management process of students as an important role, which simplifies the management process and improves the efficiency.

\section{Examples of Class Management using DingTalk}

The application of DingTalk in primary or secondary schools can solve the problem of teaching management between teachers and students ${ }^{[7,8]}$. There is a high school "teaching class" example to introduce the specific application of class management.

The class teacher logs in DingTalk and adds nine students as friends. The class teacher can create a team or a class. The registration information is filled with the actual information of teachers, students and parents which are added as team members. The class teacher configs the console and adds the related projects of class management as Fig. 1 shows. 


\section{Management of class attendance}

The class teacher sets the classroom building as the check-in location during the check-in process. Based on the location error, the position within 100 meters of specific punch card in classroom building can be affirmed, and the check-in time is the attendance time. The punch card is set as a smiley face based on face recognition, so that each person can only correspond to a punch terminal. It can prevent the replacement of punch. The class teacher can keep abreast of student attendance through the mobile phone and relieve the tedious process of calling the roll.

When a student is outside the campus for a related activity, the calss teacher can request the student to sign in with the photos. It can ensure the safety of the student and keep abreast of the student.

When a student need to ask for leave when he or she is sick or has trouble at home, the student may use the function of begging off, filling in the reason for leave, and attach a picture to the class teacher for verification.

The class teacher can check and approve the above attendance situation on the mobile phone.

\section{Messages notification}

DING is a peculiar function which enables to receive the message for smart phone without APP of DingTalk or network access. Teachers can use DING to push important and urgent notifications to all members in the class in real time, as well as to get feedback from others the status of read and unread. Notifications include software internal, external calling or text message.

For example, due to strong snowfall warning tomorrow, the school will be closed for one day as Fig. 2 shows. The class teacher pushes the message to the class so as to inform the students as well as the parents. The class teacher can inform those who have not read the message. When the approval is submitted by students and the teacher is browsing, the students can send messages through DING to remind teachers approval of application. It can improve students' initiative. The class teacher releases a non-emergency message and the student askes questions to the teacher as Fig. 3 shows. They can remind the recipient if the message are unread as Fig. 4 shows.

\section{Resource sharing}

Teachers can share extra-curricular knowledge and release slogan in bulletin boards. Sharing various learning resources including assignments by DingTalk network disk can solve the problem that teachers unable to lay down assignments or share excellent information under the lectures as Fig. 5 shows.

\section{Communication between teachers and parents}

Teachers can apply for smart office phone in DingTalk. It doesn't need using private phone at work. The function help save bill expenses. In the learning process of students, the communication between teachers and parents is included. The class teacher can add parents as friends on the DingTalk and use video conferencing immediately when one or some of parents need to be communicated as Fig. 6 shows. Communication between the teachers and parents is more convenient. 


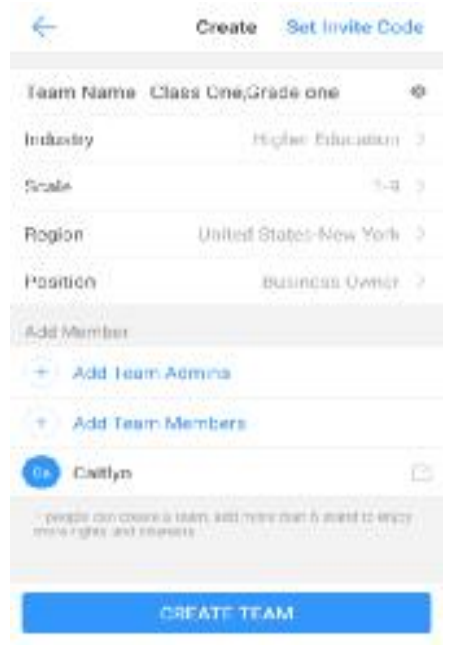

Fig. 1 Create a team

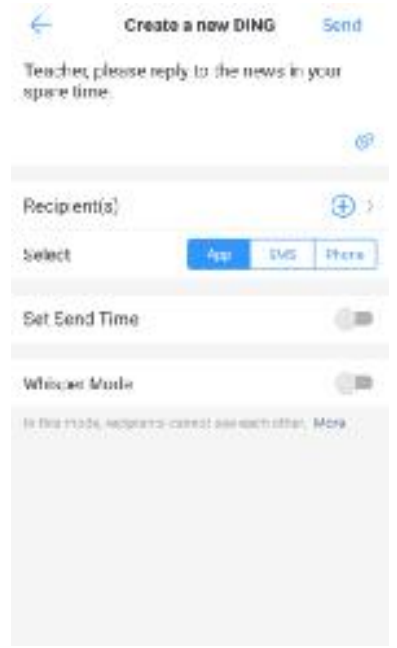

Fig.4 Reminder

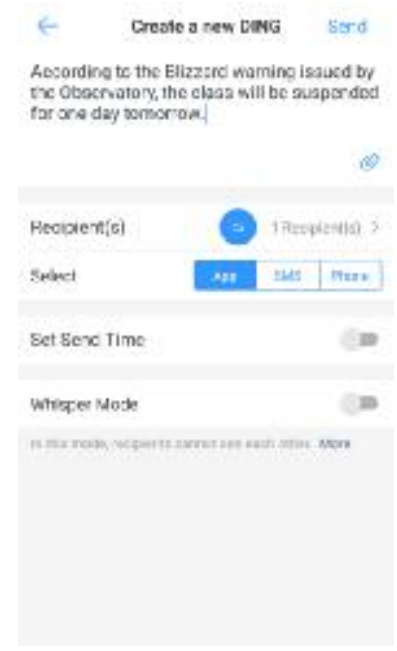

Fig.2 Release notice

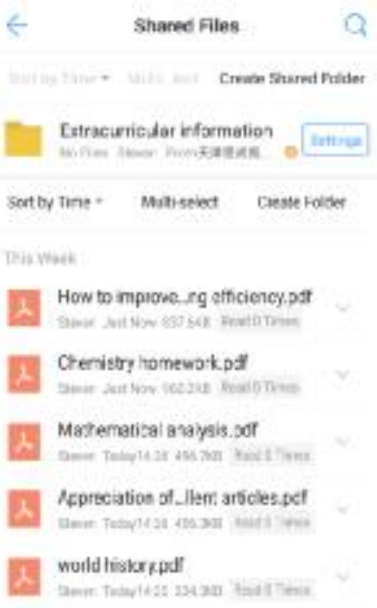

Fig. 5 Resource sharing

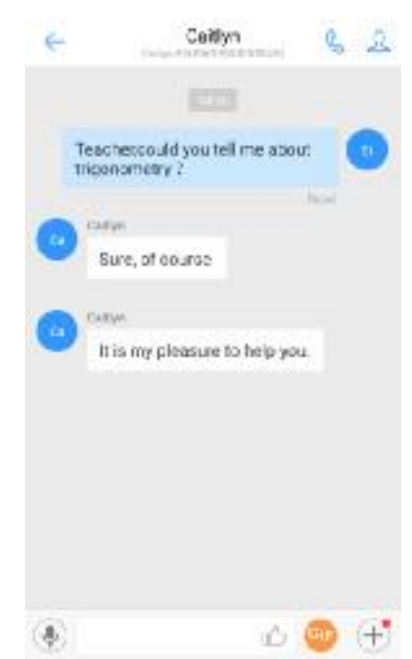

Fig.3 Teacher-student communication

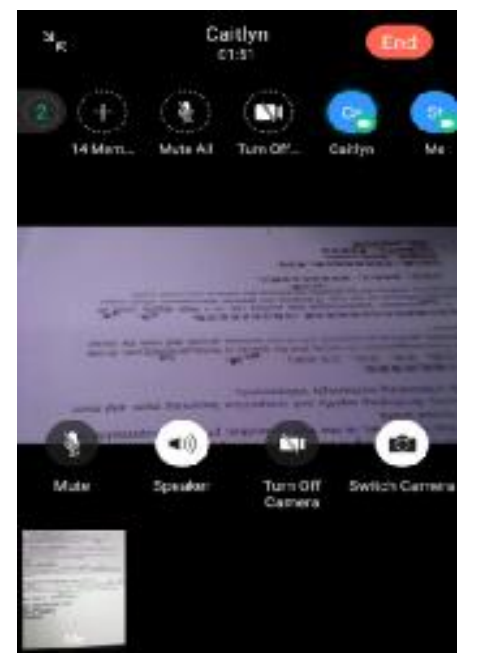

Fig. 6 Video calling

\section{Process Demonstration}

At 7:50 am, the students arrive at classroom which is specified to punch by the teachers. The student use DingTalk to punch in attendance management. The class teacher checks the students by attendance management system and obtain the attendance of class members.

After receiving the homework, the class teacher can contact the parents by the video function to report the students' learning process and to discuss the countermeasures for students who often do not finish homework or refuse to correct their mistakes.

During lunch break, the students must sign in at the destination, take pictures and report their location and other information to the class teacher when they go out for funny or shopping in order to insure their safety.

When they aren't feeling well during school and need to leave, the students can use the leave system to submit an application to the class teacher. If the class teacher do not reply, the students can use DING to remind the class teacher. After the approval of the class teacher, the approval opinions will be feedbacked in time. The class teacher releases a message by DING, to make sure their parents know they are on leave. 
The teachers can release group notification by DING, to remind students to keep themselves warm and health, and not to delay learning because of illness. Positive promotion slogan can be updated in the bulletin board, which can encourage students to be engaged in study .

The learning materials of class content for consolidating and expanding are be shared by the teachers after class by DingTalk network disk. The students can download materials and study at home. If they have problems in learning, they can communicate with their teachers to solve the puzzles through DingTalk.

\section{Conclusion}

Information technology plays an important role in the development of students by integrating home and school to jointly create a good learning environment and living environment. The teachers and parents have more chance to strengthen communication, and to work together. It can identify and solve student's problems more effective than unilateral efforts by teachers and parents. The office automation management platform DingTalk can help solve the traditional education problems, and alleviate the contradictions in the class management, and reduce the supervision difficulty of the class teacher, and improve the parents' participation in the learning of students. The example shows that the combination of class management and education informatization are conformed to the laws of education and the development trend. And it provides a reference for the application of education information in other branches.

\section{Reference}

[1] Z.H. Chen. An Analysis of Problems Encountered by Student in Contemporary ClassManagement [J]. Journal of the Chinese Society of Education, 2010, (10): 78-80.

[2] M. Zhao. Class Management's Function\&Its Meaning Orientation [J]. College of Educational Science, 2003, (06): 29-33.

[3] G.L. Li. Basic Theory of "Class Management" [J]. Journal of Educational Development, 1994, (Z1):31-35+51.

[4] Z.T. Zhu,B. He. Wisdom Education: A New Realm of Educational Informationization [J]. e-Education Research, 2012, 33(12): 5-13.

[5] F.Y. Yang. Class Management under the Network Environment [J]. Education for Chinese After school (Theory), 2009, (S4):21.

[6] H.B. Qin. Research on Job Responsibilities and Working Methods of Class Supervisors under the Network Environment [J]. China Electric Power Education,2014, (20): 40-41.

[7] S. Chen,H. Chen: DingTalk uses the most "hommization" way to improve work efficiency [J]. Southern entrepreneur, 2016, (11): 82-83.

[8] Y.Z. Sun,B. Wang. Feasibility of the Use of Dingtalk.com to Build College Counselors' Work Network Management Platform [J]. The Guide of Science \& Education (the last issue), 2016, (03): 9-10. 